Tohoku J. exp. Med., 1988, 155, 159-164

\title{
Plasma Paracetamol Concentrations Measured by Fluorescence Polarization Immunoassay and Gastric Emptying Time
}

\author{
Fumiaki Koizumi, Takeshi Kawamura, Akira Ishimori, \\ Hiroko Ebina and Michinori Satoh* \\ Department of Clinical and Laboratory Medicine, Tohoku \\ University School of Medicine, Sendai 980 and ${ }^{*}$ Sendai \\ Teishin Hospital, Sendai 980
}

\begin{abstract}
Koizumi, F., Kawamura, T., Ishimori, A., Ebina, H. and Satoh, M. Plasma Paracetamol Concentrations Measured by Fluorescence Polarization Immunoassay and Gastric Emptying Time. Tohoku J. exp. Med., 1988, 155 (2), 159-164Radionuclide labeled gastric emptying was compared with plasma paracetamol (acetaminophen) concentration measured by fluorescence polarization immunoassay. A significant correlation was found between both gastric emptying half-time of radionuclide $\left(t_{1 / 2}\right)$ and \% isotope remained in the region of the stomach and paracetamol absorption kinetic parameters. The strongest correlation was found between $t_{1 / 2}$ and the time required to reach the peak plasma level of paracetamol $(\mathrm{r}=0.680, p<0.01)$. This study indicates that simple paracetamol marker method has enabled an indirect quantitative measurement of gastric emptying by sampling at varying time intervals. —— paracetamol ; gastric emptying; fluorescence polarization immunoassay
\end{abstract}

Over the past few years, several disorders of gastric motility leading to a delayed or rapid gastric emptying have been reported (Minami and McCallum 1984 ; Horowitz et al. 1985), and thus the use for measuring gastric emptying is essential for understanding physiological and clinical problems associated with those disorders. In these years a variety of methods have been developed to measure the rate of gastric emptying. The general methods currently used for evaluating gastric emptying are (1) intubative techniques (Hunt and Spurrell 1951 ; Goldstein and Boyle 1965; George 1968), (2) radiologic techniques (Cannon 1902; Abe 1981), (3) radioisotopic techniques utilizing external scanning (Griffith et al. 1966; Chaudhuri 1974; Horowitz et al. 1982), and (4) ultrasound techniques (Bateman and Whittingham 1982). The use of blood concentration of paracetamol, which is not absorbed from the stomach but rapidly from the small bowel, has also been used as an indirect measure of the rate of gastric emptying (Heading et al. 1973 ; Nimmo et al. 1975; Harasawa et al. 1979; Goldstraw and

Received February 22, 1988; revision accepted for publication May 11, 1988. 
Bach 1981; Nakanome et al. 1982 ; Ogoshi et al. 1982 ; Marsh et al. 1984 ; Maddern et al. 1985).

Spectrophotometric method (Harasawa et al. 1979; Nakanome et al. 1982 ; Ogoshi et al. 1982), gas-chromatography (Heading et al. 1973 ; Nimmo et al. 1975 ; Goldstraw and Bach 1981) and high-pressure liquid chromatography (Marsh et al. 1984 ; Maddern et al. 1985) have been used exclusively as a technique of choice for determining paracetamol in plasma. The disadvantage of each method such as requiring much time and efforts has also been pointed out. Recently, a reliable, simple and rapid assay for paracetamol based on the principle of fluorescence polarization immunoassay (FPIA) has been available, and therefore we compared radionuclide-labeled gastric emptying with plasma paracetamol concentration.

\section{Materials and Methods}

The study subjects included 7 patients with gastritis, 11 patients with gastric ulcer, 6 patients with duodenal ulcer and 1 patient with gastric cancer. Informed consent was obtained from all subjects. The gastric emptying test was performed after an overnight fast. The test procedures used were described previously (Koizumi et al. 1987) : Briefly, a standard, Japanese style hospital lunch for patients comprising rice water, bean or misosoup, a raw egg and a lactic acid beverage (25 g carbohydrate, $6.5 \mathrm{~g}$ fat and $10.2 \mathrm{~g}$ protein, $206 \mathrm{Kcal}$ ) and $1.5 \mathrm{~g}$ paracetamol was prepared. In the rice water $1 \mathrm{mCi}$ dose of ${ }^{99 m} \mathrm{Tc}-\mathrm{Sn}$ colloid was mixed. Meal and paracetamol were consumed within 5 min. Immediately thereafter, the amount of isotope remaining in the stomach was determined at 15-min intervals for $65 \mathrm{~min}$ using a gamma camera (LFOV, Shimadzu, Kyoto) and results were recorded on videotape. After the area of interest was obtained based on the recorded data, the gastric emptying rate was determined by Scinti-pac 230 (Shimadzu) from the decreasing intragastric fraction of the total radioactivity determined at sequential scanning periods and

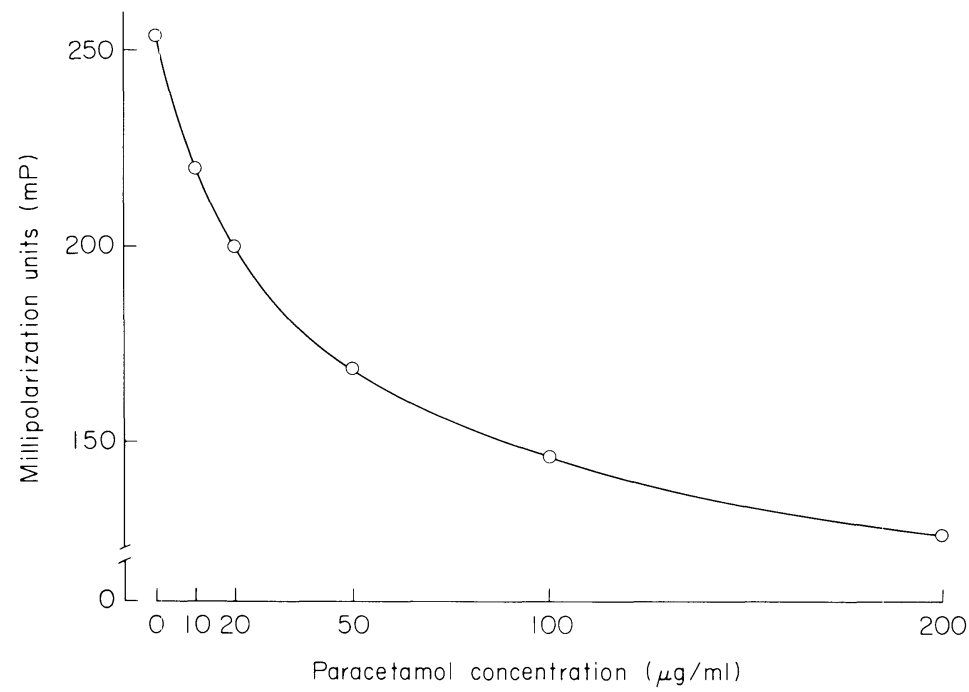

Fig. 1. Standard curve showing the relationship between the decreasing polarization of fluorescence and increasing levels of added paracetamol in serum. 
TABle 1. Precision of paracetamol concentration by assaying three control sera 10 times in one assay and in 10 consecutive assays

\begin{tabular}{ccrr}
\hline $\begin{array}{c}\text { Target level } \\
(\mu \mathrm{g} / \mathrm{ml})\end{array}$ & $\begin{array}{c}\text { Measured level } \\
\text { mean } \pm \text { s.D. }(\mu \mathrm{g} / \mathrm{ml})\end{array}$ & $\% \mathrm{CV}$ & $\%$ Bias \\
\hline \multicolumn{3}{c}{ Within-assay precision } \\
12.5 & $5.6 \pm 0.7$ & 12.1 & -10.4 \\
25 & $12.6 \pm 0.4$ & 3.2 & 0.8 \\
& $26.0 \pm 0.8$ & 2.9 & 4.0 \\
6.25 & Between-assay precision & & \\
12.5 & $6.0 \pm 0.4$ & 7.1 & -4.0 \\
25 & $13.4 \pm 1.1$ & 7.9 & 7.2 \\
& $26.2 \pm 0.9$ & 3.5 & 4.8 \\
\hline
\end{tabular}

S.D., standard deviation ; CV, coefficient of variation; $\%$ Bias $=100 \times$ (measured concentration - target concentration)/target concentration

the half-life $\left(t_{1 / 2}\right)$ of the meal in the stomach was calculated. Counts were taken in the standing position and subjects were permitted to move freely during counting.

Blood samples were taken at $-30 \mathrm{~min}$ before meal and at 5, 20, 35, 50,65 and $95 \mathrm{~min}$ after ingestion for assessing paracetamol absorption parameters.

Paracetamol concentrations in plasma were estimated in duplicate with a FPIA system (TDX ${ }^{\circledR}$, Dainabot, Irving, TX, USA). The principles of FPIA have been reviewed (Jolley 1981). Fig. 1 shows a typical assay standard curve of paracetamol in which the polarization in arbitrary units of fluorescein-labeled paracetamol bound to the antibody is plotted against the concentration of paracetamol in microgram per milliliter.

Paracetamol control samples for precision studies were prepared by dissolving paracetamol $200 \mathrm{mg}$ in $200 \mathrm{ml}$ methanol and were serially diluted to $6.25,12.5$ and $25 \mu \mathrm{g} / \mathrm{ml}$ with drug-free human serum. The precision data obtained are summarized in Table 1. Intra- and inter-assay reproducibility was good.

Coefficients of the correlations ( $r$ ) between the $t_{1 / 2}$ of radionuclide and plasma paracetamol concentrations measured at the 6 different postdose times, peak concentration and time to peaked concentration $\left(t_{\max }\right)$, and between the \% isotope retention and the area under the plasma paracetamol concentration-time curves (AUC) up to 20, 35, 50 and $65 \mathrm{~min}$ postdose were calculated by the least-squares regression analysis.

\section{RESUlts}

The mean isotope remaining in the stomach was $75.6 \pm 10.8 \%, 54.5 \pm 17.8 \%$, $37.7 \pm 16.7 \%$ and $27.8 \pm 16.0 \%$ at $20,35,50$ and $65 \mathrm{~min}$, respectively. The respective mean paracetamol concentrations were $4.1 \pm 6.0 \mu \mathrm{g} / \mathrm{ml}, 10.7 \pm 8.6 \mu \mathrm{g} / \mathrm{ml}$, $14.6 \pm 8.2 \mu \mathrm{g} / \mathrm{ml}, 15.7 \pm 7.4 \mu \mathrm{g} / \mathrm{ml}, 15.4 \pm 6.4 \mu \mathrm{g} / \mathrm{ml}$ and $14.0 \pm 4.8 \mu \mathrm{g} / \mathrm{ml}$ at 5,20 , $35,50,65$ and $95 \mathrm{~min}$. The mean peak plasma paracetamol concentration occurred at 50 min after the oral dosing (Fig. 2).

The $t_{1 / 2}$ value of gastric emptying time derived from the isotope technique was compared with the plasma concentrations of paracetamol measured at 5 to 95 min postdose and the time required to reach the peak. As listed in Table 2, a significant correlation was found between the $t_{1 / 2}$ value for radionuclide and both 

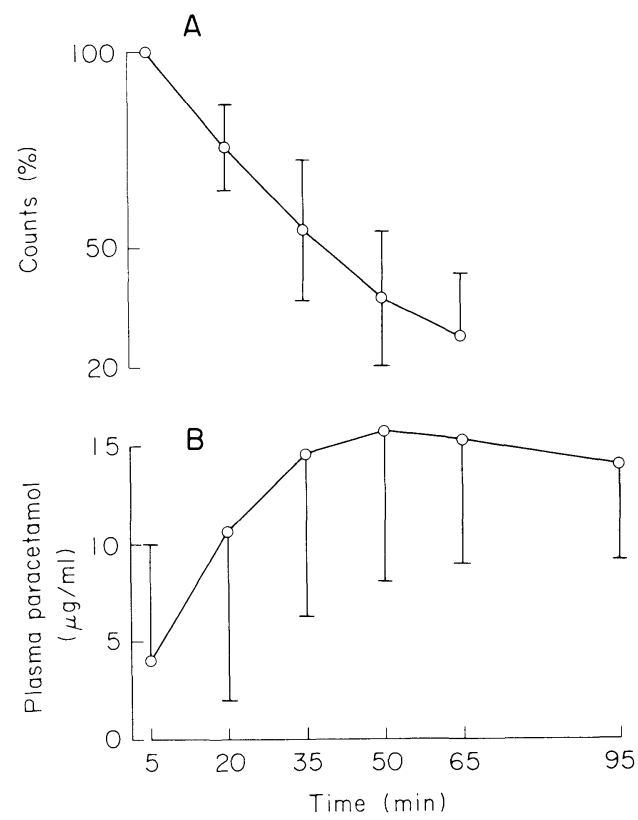

Fig. 2. Gastric emptying rate (A) and paracetamol concentration-time course (B) in 25 subjects. Counts at 5 min after meal were normalized to $100 \%$ (A). Results are shown in terms of mean \pm s.D.

TABLE 2. Relationship between gastric emptying $t_{1 / 2}$ measured with radionuclide technique and paracetamol absorption parameters, and between \% isotope retention and $A U C$ values $(\mu \mathrm{g} \cdot \mathrm{hr} / \mathrm{ml})$ calculated up to $65 \mathrm{~min}$ postdose

\begin{tabular}{|c|c|c|}
\hline & $\mathrm{r}$ & $p$ \\
\hline \multicolumn{3}{|l|}{$\begin{array}{l}t_{1 / 2} \text { vs. plasma paracetamol } \\
\text { concentration at time }\end{array}$} \\
\hline 5 & 0.119 & n.s. \\
\hline 20 & -0.300 & n.s. \\
\hline 35 & -0.414 & $<0.05$ \\
\hline 50 & -0.232 & n.s. \\
\hline 65 & -0.096 & n.s. \\
\hline 95 & 0.204 & n.s. \\
\hline $\begin{array}{l}\mathrm{t}_{1 / 2} \text { vs. peak plasma paracetamol } \\
\text { concentration }\end{array}$ & -0.163 & n.s. \\
\hline $\begin{array}{l}t_{1 / 2} \text { vs. time of peak plasma } \\
\text { paracetamol }\end{array}$ & 0.680 & $<0.01$ \\
\hline \multicolumn{3}{|l|}{$\%$ Isotope retention at time } \\
\hline 20 vs. $\mathrm{AUC}_{0 \rightarrow 20}$ & -0.304 & n.s. \\
\hline 35 vs. $\mathrm{AUC}_{0 \rightarrow 35}$ & -0.519 & $<0.01$ \\
\hline 50 vs. $\mathrm{AUC}_{0 \rightarrow 50}$ & -0.398 & $<0.05$ \\
\hline 65 vs. $\mathrm{AUC}_{0 \rightarrow 65}$ & -0.352 & n.s. \\
\hline
\end{tabular}

n.s., not significant. 
plasma paracetamol level at 35 min after meal $(r=-0.414, p<0.05)$ and the time required to reach the peak $(\mathrm{r}=0.680, p<0.01)$. When the percent count of isotope in the stomach was compared with the AUC, there was a significant correlation between percent count at $35 \mathrm{~min}$ and $\mathrm{AUC}$ from 0 to $35 \mathrm{~min}(\mathrm{r}=$ $-0.519, p<0.01)$, and percent count at $50 \mathrm{~min}$ and $\mathrm{AUC}$ from 0 to $50 \mathrm{~min}(\mathrm{r}=$ $-0.398, p<0.05)$.

\section{Discussion}

FPIA becomes increasingly popular for plasma drug determination because of its rapidity, simplicity, specificity and reproducibility. Only $50 \mu \mathrm{l}$ of plasma is needed and it does not require extraction as in previously established paracetamol assay methods (Heading et al. 1973; Nimmo et al. 1975; Harasawa et al. 1979; Goldstraw and Bach 1981; Nakanome et al. 1982 ; Ogoshi et al. 1982 ; Marsh et al. 1984 ; Maddern et al. 1985).

There were considerable interindividual variations in the rate at which orally administered paracetamol was absorbed in this study. The peak plasma concentration of paracetamol varied from $6.4 \mu \mathrm{g} / \mathrm{ml}$ to $36.9 \mu \mathrm{g} / \mathrm{ml}$ and the time required to reach peak concentrations ranged from 20 to $95 \mathrm{~min}$ after ingestion. Significant correlation exists between both gastric emptying $t_{1 / 2}$ measured with the radionuclide technique and the $\%$ count in the stomach and paracetamol absorption parameters. The statistically strongest correlation was found between the $t_{1 / 2}$ and $t_{\max }$. The absorption of paracetamol is, therefore, likely to be dependent on the rate of gastric emptying.

Previously reported studies have failed to take frequent samples of plasma, and the plasma paracetamol concentration at $45 \mathrm{~min}$ after ingestion was used as the indirect indicator of gastric emptying rate (Harasawa et al. 1979 ; Nakanome et al. 1982 ; Ogoshi et al. 1982). Results obtained in this study verify that the time required to reach the peak as measured by frequent blood sampling reflects more precisely the radionuclide-assessed gastric emptying time.

\section{References}

1) Abe, T. (1981) Comparative studies on various operations for peptic ulcer. Nippon Shokaki Geka Gakkai Zasshi, 14, 1167-1177. (Japanese)

2) Bateman, D.N. \& Whittingham, T.A. (1982) Measurement of gastric emptying by real-time ultrasound. Gut, 23, 524-527.

3) Cannon, W.B. (1902) The movements of the intestines studied by means of the röntgen rays. Amer. J. Physiol., 6, 251-277.

4) Chaudhuri, T.K. (1974) Use of ${ }^{99 \mathrm{~m} T c-D T P A}$ for measuring gastric emptying time. J. nucl. Med., 15, 391-395.

5) George, J.D. (1968) New clinical method for measuring the rate of gastric emptying : The double sampling test meal. Gut, 9, 237-242.

6) Goldstein, H. \& Boyle, J.D. (1965) The saline load test: A bedside evaluation of gastric retention. Gastroenterology, 49, 375-380.

7) Goldstraw, P. \& Bach, P. (1981) Gastric emptying after oesophagectomy as assessed 
by plasma paracetamol concentrations. Thorax, 36, 493-496.

8) Griffith, G.H., Owen, G.M., Kirkman, S. \& Shields, R. (1966) Measurement of rate of gastric emptying using chromium-51. Lancet, 1, 1244-1245.

9) Harasawa, S., Tani, N., Suzuki, S., Miwa, M., Sakita, R., Nomiyama, T. \& Miwa, T. (1979) Gastric emptying in normal subjects and patients with peptic ulcer. Gastroenterol. jap., 14, 1-10.

10) Heading, R.C., Nimmo,J., Prescott, L.F. \& Tothill, P. (1973) The dependence of paracetamol absorption on the rate of gastric emptying. Brit. J. Pharmacol., 47, 415421.

11) Horowitz, M., Cook, D.J., Collins, P.J., Harding, P.E. \& Shearman, D.J.C. (1982) The application of techniques using radionuclides to the study of gastric emptying. Surg. Gynecol. Obstet., 155, 737-744.

12) Horowitz, M., Collins, P.J. \& Shearman, D.J.C. (1985) Disorders of gastric emptying in humans and the use of radionuclide techniques. Arch. intern. Med., 145, 14671472 .

13) Hunt, J.N. \& Spurrell, W.R. (1951) The pattern of emptying of the human stomach. J. Physiol. (Lond.), 113, 157-168.

14) Jolley, M.E. (1981) Fluorescence polarization immunoassay for the determination of therapeutic drug levels in human plasma. J. analyt. Toxicol., 5, 236-240.

15) Koizumi, F., Kawamura, T., Ishimori, A., Ebina, H. \& Satoh, M. (1987) Correlation between gastric emptying time and the response of pancreatic polypeptide to test meals in peptic ulcer diseases. Tohoku J. exp. Med., 151, 275-281.

16) Maddern, G., Miners, J., Collins, P.J. \& Jamieson, G.G. (1985) Liquid gastric emptying assessed by direct and indirect techniques: Radionuclide labelled liquid emptying compared with a simple paracetamol marker method. Aust. N.Z.J. Surg., 55, Aust. N.Z.J. Surg. 203-206.

17) Marsh, R.H.K., Spencer, R. \& Nimmo, W.S. (1984) Gastric emptying and drug absorption before surgery. Brit. J. Anaesth., 56, 161-164.

18) Minami, H. \& MaCallum, R.W. (1984) The physiology and pathophysiology of gastric emptying in humans. Gastroenterology, 86, 1592-1610.

19) Nakanome, C., Akai, H., Hongo, M., Imai, N., Toyota, T., Goto, Y., Okuguchi, F. \& Komatsu, K. (1982) Disturbances of the alimentary tract motility and hypermotilinemia in the patients with diabetes mellitus. Nippon Shokakibyo Gakkai Zasshi, 79, 2207-2215. (in Japanese with English abstract)

20) Nimmo, W.S., Heading, R.C., Wilson, J., Tothill, P. \& Prescott, L.F. (1975) Inhibition of gastric emptying and drug absorption by narcotic analgesics. Brit. J. clin. Pharmacol., 2, 509-513.

21) Ogoshi, K., Makuuchi, H., Kondoh, Y., Tajima, T. \& Mitomi, T. (1982) Effects of selective proximal vagotomy on gastric acid output, serum gastrin responses to a test meal, gastric emptying and lower esophageal sphincter function - with particular reference to postvagotomy dysphagia. Nippon Geka Gakkai Zasshi, 83, 548-555. (in Japanese with English abstract) 